\title{
Relationship Between Serum Ferritin, TIBC Level and Helicobacter pylori Infection
}

\author{
Kaveh Tari, ${ }^{1}$ Zahra Shamsi, ${ }^{1}$ Arezou Rahimi, ${ }^{2}$ and Amir Atashi ${ }^{1,}{ }^{*}$ \\ ${ }^{1}$ Department of Hematology, Faculty of Medical Sciences, Tarbiat Modares University, Tehran, IR Iran \\ ${ }^{2}$ Department of Immunology, Faculty of Medicine, Shahid Beheshti University of Medical Sciences, Tehran, IR Iran \\ "Corresponding author: Amir Atashi, Department of Hematology, Faculty of Medical Sciences, Tarbiat Modares University, Tehran, IR Iran. E-mail: atashia@gmail.com
}

Received 2015 March 25; Accepted 2015 March 25.

\begin{abstract}
Background: In iron deficiency anemia (IDA), serum ferritin level is decreased and total iron binding capacity (TIBC) is increased Objectives: In this study the relationship between $H$. pylori infection and iron deficiency anemia were studied.

Methods: This research was a cross-sectional study. TIBC and ferritin levels were measured in 133 patients, suspected to H. pylori infection, then serum levels of IgM and IgG antibody against $H$. pylori infection were measured

Results: From 133 patients, 97 were females (72.93\%) and 36 males (28.07\%), 36 of them (23 women and 13 men) have a TIBC levels more than $400 \mathrm{ug} / \mathrm{dL}$ and ferritin levels were less than $12 \mathrm{ng} / \mathrm{dL}$. Twenty patients had IgG antibodies and 5 patients had IgM against H. pylori.
\end{abstract}

Conclusions: The results show the association between H. pylori infection and increased levels of TIBC and decreased serum ferritin.

Keywords: Ferritin, Total Iron binding Capacity, Iron Deficiency Anemia, Helicobacter pylori Infection

\section{Background}

Iron deficiency anemia is the most common cause of anemia in the worldwide and due to iron deficiency for erythropoiesis. Its prevalence is high in children and during growth [1]. There are several factors in incidence anemia. The main reason is the lack of iron in the diet of children (dietary iron); in adult males is almost result from chronic blood loss due to gastrointestinal bleeding (gastrointestinal lesions leading to blood loss include peptic ulcers) and menstrual bleeding in women $[2,3]$. Clinical and laboratory characteristics may helpful to detect of this anemia. Common symptoms of anemia include fatigue, lethargy, decreased exercise tolerance, weakness, weight loss, reduced growth and the specific symptoms such as unusual desire to eat food (pica) [4]. Most significant laboratory finding including decreased MCV (mean cell volume), MCHC (mean cell hemoglobin concentration) and levels of serum ferritin and increased TIBC (total iron binding capacity). Peripheral blood of patients is hypochromic microcytic RBC (red blood cell) [5]. Helicobacter pylori infection is causes chronic gastritis, peptic ulcer and gastric carcinoma. In addition, it have extra gastric symptom. Various methods used to identify patients infected with H. pylori, invasive procedures such as endoscopic mucosal biopsy and tissue culture, noninvasive techniques include urea breath test and evaluation of serum antibodies against $H$. pylori. Humoral immune response to $H$. pylori in- fection with production of IgA and IgG, IgM antibodies. Antibodies can be measured and detected by serologic tests [6]. Various studies are suggesting that $H$. pylori infection as a risk factor for iron deficiency anemia. Probably mechanisms include decreased secretion of HCL (Hydrochloric acid), achlorhydria in gastric mucosa that reduces the absorption of iron, also absorbed iron by $H$. pylori bacteria is the one of the mechanism $[7,8]$.

\section{Objectives}

In this study the relationship between $H$. pylori infection and iron deficiency anemia were studied.

\section{Methods}

In this cross-sectional study, 133 patients who complained of digestive problems, abdominal pain, nausea and vomiting were referred to Imam Khomeini hospital laboratory of Tehran were selected. These patients were suspected to infection with H. pylori. At first TIBC and ferritin levels were measured. TIBC level measured by biochemical BT3000 autoanalyzer (Biotechnica instruments.USA). Up to $400 \mu \mathrm{g} / \mathrm{dL}$ was considered the increased level and serum ferritin levels were measured by ELISA method by protocol of kit Pishtazteb (IRAN) and less than $12 \mathrm{ng} / \mathrm{dL}$ was considered reduced level. Then the people 
with reduced levels of serum ferritin and TIBC increased were considered as sample, and the others as control and IgM and IgG antibodies against $H$. pylori were measured in them. Finally, statistical analysis by using SPSS-22 software and $\chi^{2}$ and t-tests were performed.

\section{Results}

Of 133 patients that referred to laboratory, 97 of them were women and 36 were men. The most age range was 44 -35 years.

\subsection{Results of Serum Ferritin and TIBC Level}

Of 133 patients, 36 patients have serum ferritin levels less than $12 \mathrm{ng} / \mathrm{dL}$ and TIBC levels more than $400 \mu \mathrm{g} / \mathrm{dL}$. Finally significant relationship between sex and TIBC and ferritin not found.

\subsection{Serological Results of H. pylori Test}

H. pylori infection serological results showed that of 36 patients with icreased serum TIBC level and decreased serum ferritin level, 20 of them were positive titer for IgG (up to 100) and 5 of them were positive titer for IgM (up to 20) and in control group who serum TIBC and ferritin levels were normal, one case was positive titer for IgG (up to 100) antibodies against $H$. pylori.

\subsection{Results of Stastical Analysis}

T-test results has shown significant relationship between the serum TIBC and ferritin level and H. pylori infection $(\mathrm{P}=0.05)$. Also, no significant relationship was found between gender and $H$. pylori infection.

Table 1. Distribution of Gender

\begin{tabular}{lcc}
\hline Gender & Frequency & Percent \\
\hline Female & 97 & 72.9 \\
Male & 36 & 27.1 \\
Sum & 133 & 100 \\
\hline
\end{tabular}

Table 2. Results ${ }^{\mathrm{a}}$

\begin{tabular}{lcc}
\hline Results & TIBC $\leftarrow$, Ferittin $\leftarrow$ & TIBC $\uparrow$, Ferittin $\downarrow$ \\
\hline HP/IgG & 1 & 20 \\
HP/IgM & 0 & 5 \\
HP/IgG, IgM & 96 & 11
\end{tabular}

Abbreviation: HP: Helicobacter pylori.

${ }^{\text {a }}$ normal: $\leftarrow$, increase: $\uparrow$, decrease: $\downarrow$.

\section{Discussion}

Iron deficiency anemia is the most common cause of anemia in the worldwide. The anemia is usually seen when the amount of iron in food cannot compensate iron requirement or there is an external hemorrhage. This anemia is classified into three stages: iron depletion stage, iron deficient along with erythropoiesis and the last stage is iron deficiency. In blood loss, iron storage used and then ended iron stores, erythropoisis limited and finally lead to iron deficiency anemia [9]. In this study, the patient had a decrease in ferritin and control group did not have any inflammatory disease, so the effect of inflammation on serum ferritin levels was removed. Many studies [3, 5, 7, 10] have shown the relationship between $H$. pylori infection and iron deficiency anemia. Mozon et al. in the study had results similar to our results, in this study patients with H.pylori infection and IDA were treated for $H$. pylori and in patients treated significantly improve IDA were observed, therefore concluded that the infection can cause IDA that was consistent with our results [11]. Konno et al. in two separate study showed that in patients with iron deficiency anemia, treatment of H.pylory infection can improve IDA, therefore IDA associated with infection which this results showed that are consistent with the our results [12].

The main mechanism including chronic bleeding, iron intake by bacteria and reduce stomach achorhydria and decrease iron absorption. In this study used IDEAL ELISA kit (Iran) for the diagnosis of H.pylori which has a sensitivity of $96.8 \%$ and specificity of $73 \%$. Antibody against H. pylori IgG and IgM were measured. The IgG antibodies in $94 \%$ - 95\% of patients, approximately 2 months after the entry into body will be positive and after eradication bacteria and infection remains positive up to a year or more, also the antibodies of the IgM class insensitive indicator of acute infection. In this study indicated that no significant relationship between gender with serum TIBC and ferritin level and $H$. pylori outbreak. Several studies have shown that H. pylori infection leads to decreased serum ferritin level. The study also showed that $H$. pylori infection can lead to decreased of serum ferritin and increased of TIBC levels. Parkinson et al. and Berg et al. in two studies have shown that $H$. pylori infection cause decrease in serum ferritin level that consistent with our results $[10,13]$. Also Choe et al. have shown that H. pylori result in IDA [8]. Milman et al. show H. pylori infection affects iron metabolism in humans [14] and Seo et al. show serum ferritin levels are reduced in children with $H$. pylori infection therefore the $H$. pylori infection may lead to iron deficiency in children [15].

Many studies $[3,7,11,13]$ have shown the relationship between $H$. pylori infection and reduced serum ferritin levels and other studies have not confirmed this relationship. 
This study show this relationship, therefore its seems important to assess the digestive tract for the management of patients with IDA. H. pylori with or without gastric body atrophy should always be considered as a possible cause of IDA. It is recommended that further studies on other parameters of iron deficiency anemia done.

\section{Acknowledgments}

This study was supported by Emam Khomeini hospital.

\section{Footnotes}

Authors' Contribution: All authors had equal role in design, work, statistical analysis and manuscript writing

Conflict of Interest: The authors declare that they have no conflict of interest in this work.

Funding/Support: Tarbiat Modares University, Tehran.

\section{References}

1. Killip S, Bennett JM, Chambers MD. Iron deficiency anemia. Am Fam Physician. 2007;75(5):671-8. [PubMed: 17375513].

2. Clark SF. Iron deficiency anemia. Nutr Clin Pract. 2008;23(2):128-41. doi: 10.1177/0884533608314536. [PubMed: 18390780].

3. Alton I, Stang M, Story M. In: Iron deficiency anemia. Center for leadership EATIMACN, editor. Division of epidemiology and community health; 2005. pp. 101-8.

4. Means RT. Iron deficiency anemia. Hematology. 2013;18(5):305-6. doi: 10.1179/1024533213Z.000000000197. [PubMed: 24020489].
5. Guyatt GH, Oxman AD, Ali M, Willan A, McIlroy W, Patterson C. Laboratory diagnosis of iron-deficiency anemia: an overview. J Gen Intern Med. 1992;7(2):145-53. [PubMed:1487761].

6. Raymond J, Sauvestre C, Kalach N, Bergeret M, Dupont C. Immunoblotting and serology for diagnosis of Helicobacter pylori infection in children. Pediatr Infect Dis J. 2000;19(2):118-21. [PubMed: 10693997].

7. Hirsch S, de la Maza MP. Nutrition and Aging. 6. Karger Publishers; 2002. pp. 97-108.Functional changes in the gastrointestinal system.

8. Choe YH, Kwon YS, Jung MK, Kang SK, Hwang TS, Hong YC. Helicobacter pylori-associated iron-deficiency anemia in adolescent female athletes. J Pediatr. 2001;139(1):100-4. doi: 10.1067/mpd.2001.114700. [PubMed: 11445801].

9. Crichton R, Boelaert JR. Inorganic biochemistry of iron metabolism: from molecular mechanisms to clinical consequences. John Wiley and Sons; 2001.

10. Parkinson AJ, Gold BD, Bulkow L, Wainwright RB, Swaminathan B, Khanna B, et al. High prevalence of Helicobacter pylori in the Alaska native population and association with low serum ferritin levels in young adults. Clin Diagn Lab Immunol. 2000;7(6):885-8.

11. Monzon H, Forne M, Esteve M, Rosinach M, Loras C, Espinos JC, et al. Helicobacter pylori infection as a cause of iron deficiency anaemia of unknown origin. World J Gastroenterol. 2013;19(26):4166-71. doi: 10.3748/wjg.v19.i26.4166. [PubMed: 23864779].

12. Konno M, Muraoka S, Takahashi M, Imai T. Iron-deficiency anemia associated with Helicobacter pylori gastritis.JPediatr Gastroenterol Nutr. 2000;31(1):52-6. [PubMed: 10896071].

13. Berg G, Bode G, Blettner M, Boeing H, Brenner H. Helicobacter pylori infection and serum ferritin: A population-based study among 1806 adults in Germany. Am J Gastroenterol. 2001;96(4):1014-8. doi: 10.1111/j.1572-0241.2001.03686.x. [PubMed: 11316140].

14. Milman N, Rosenstock S, Andersen L, Jorgensen T, Bonnevie O. Serum ferritin, hemoglobin, and Helicobacter pylori infection: a seroepidemiologic survey comprising 2794 Danish adults. Gastroenterology. 1998;115(2):268-74. [PubMed: 9679031].

15. Seo JK, Ko JS, Choi KD. Serum ferritin and Helicobacter pylori infection in children: a sero-epidemiologic study in Korea.J Gastroenterol Hepatol. 2002;17(7):754-7. [PubMed: 12121504]. 